\title{
RANCANG BANGUN SISTEM KEAMANAN PADA SEPEDA MOTOR MENGGUNAKAN SMS GATEWAY BERBASIS MIKROKONTROLLER
}

\author{
Ferdinand Nur Adam Wijaya, Sidik Noertjahjono, Yosep Agus Pranoto \\ Program Studi Teknik Informatika S1, Fakultas Teknologi Industri \\ Institut Teknologi Nasional Malang, Jalan Raya Karanglo km 2 Malang, Indonesia \\ ferdinandnuradam@gmail.com
}

\begin{abstract}
ABSTRAK
Dengan berkembangnya jaman yang sangat pesat, maka kebutuhan tiap manusia juga semakin meningkat namu tidak semua manusia mampu memenuhi kebutuhan setiap saat. Berdasarkan data yang dirilis oleh pihak polres Malang dan Polres Malang Kota kasus pencurian sepeda motor mendominasi, terbukti dari data sepanjang tahun 2019 telah tercatat ada 248 kasus curanmor yang terjadi di Malang Kota.

Dengan perkembangan teknologi sekarang, pengembangan dalam sistem proteksi motor juga sangat di butuhkan dalam mengantisipasi terjadinya kehilangan motor yang kian marak. Penambahannya dapat berupa sensor sidik jari untuk mengaktifkan sistem kelistrikan pada motor dan SMS Gateway yang berfungsi untuk memberi informasi pada pemilik sepeda motor ketika motor dalam keadaan aktif

Berdasarkan hasil perancangan sitem, implementasi hingga pengujian yang memanfaatkan sms gateway dari modul GSM dan melacak lokasi dengan modul GPS dengan rentan waktu 3 hingga 4 detik dan selisih jarak yang di hasilkan yaitu $1,5 \mathrm{~m}$
\end{abstract}

.Kata kunci : Sensor Sidik Jari, Mikrokontroller, Modul GSM, Modul GPS,

\section{PENDAHULUAN}

Dengan berkembangnya jaman yang sangat pesat, maka kebutuhan tiap manusia juga semakin meningkat namu tidak semua manusia mampu memenuhi kebutuhan setiap saat. Berdasarkan data yang dirilis oleh pihak polres Malang dan Polres Malang Kota kasus pencurian sepeda motor (curanmor) mendominasi alias menduduki peringkat tertinggi, hal tersebut diakui Wakapolresta Malang Kota, Kompol Arie Trestiawan, terbukti dari data sepanjang tahun 2019 telah tercatat ada 248 kasus curanmor yang terjadi di Malang Kota.

Untuk itulah pengembangan dalam sistem proteksi motor juga sangat di butuhkan dalam mengantisipasi terjadinya kehilangan motor yang kian marak. Penambahannya dapat berupa sensor sidik jari untuk mengaktifkan sistem kelistrikan pada motor dan SMS Gateway yang berfungsi untuk memberi informasi pada pemilik sepeda motor ketika motor dalam keadaan aktif, penelitian ini di laksanakan untuk mengurangi kasus pencurian motor dan dengan ini para pemilik motor lebih merasa aman ketika motor jauh dari jangkauannya karena segala bentuk informasi dapat dengan mudah di dapat melalui fitur sms yang dimana fitur ini yang sangat mudah di pahami oleh semua kalangan masyarakat disamping itu fitur sms tidak bergantung pada internet dan bisa dikirim dengan mudah selama ada sinyal seluler dan teknologi SMS tidak memiliki batasan terhadap perangkat keras, perangkat lunak, dan ketersediaan atau kecepatan internet. Dalam fitur ini membuat SMS dapat menjangkau semua perangkat telefon genggam, hingga yang paling dasar sekalipun.

\subsection{Rumusan Masalah}

Setelah dipaparkan pada latar belakang, maka dapat disimpulkan dengan masalah sebagai berikut :

1. Bagaimana merancang dan membangun sistem kemanan motor yang dapat dimonitoring dalam bentuk short message service (SMS) ?

2. Bagaimana melakukan pengujian pada sistem keamanan motor dalam bentuk short message service (SMS) dengan waktu yang sudah ditentukan?

\subsection{Batasan Masalah}

Agar dalam penulisan penelitian yang dibuat tidak meluas, maka penelitian ini memiliki batasan masalah sebagai berikut:

1. Monitoring dan pengendalian pada kelistrikan motor tidak menggunakan platform website

2. Monitoring dan pengendalian pada kelistrikan motor hanya menggunakan platform handphone dan berbentuk SMS

3. Untuk transmisi data monitoring dan pengendalian dari arduino ke handphone berbentuk SMS menggunakan modul GSM SIM800L

4. Bahasa pemrograman yang digunakan yaitu $C$ arduino untuk arduino.

\subsection{Tujuan}

Adapun tujuan yang diharapkan dari pelaksanaan penelitian ini sebagai berikut : 
1. Untuk merancang dan membangun sistem kemanan sistem kelistrikan motor menggunakan modul GSM SIM800L.

2. Untuk mengembangkan sistem kemanan sistem kelistrikan motor dengan sistem monitoring berbentuk SMS menggunakan handphone dengan bantuan modul GSM SIM800L

3. Untuk mengembangkan keamanan pada kelistrikan motor yang di monitoring dalam bentuk SMS.

\section{TINJAUAN PUSTAKA}

\subsection{Penelitian Terdahulu}

Ditahun 2017 Fernando Napitupulu, Ekki Kurniawan, S.T., M.S.c, dan Cahyantari Ekaputri,ST,MT mengembangkan perangkat yang pada saat sepeda motor dihidupkan maka pengguna diwajibkan untuk melakukan konfirmasi pada keypad atau dengan mengirimkan pesan ke nomor yang telah disediakan maka nilai input dan relay akan berubah. Apabila pengguna tidak melakukan konfirmasi sebagaimana dibutuhkan maka akan membuat perubahan yang akan memberi perintah kepada mikrokontroler untuk mengupdate posisi pengoperasian sepeda motor. Bagian yang melakukan monitoring mengenai posisi sepeda motor adalah modul GPS yang akan mengirimkan titik koordinat. Setelah pekerjaan yang dilakukan oleh modul GPS sukses, modul GSM juga akan melakukan pekerjaannya untuk mengirimkan SMS titik koordinat kepada pengguna sebagai peringatan dan mengetahui letak kendaraan. [1]

Dan pada tahun 2018, Deri Andesta dan Rian Ferdian juga mulai mengembangkan sistem kemanan pada motor, yang dimana implementasi sistem keamanan pada sepeda motor ini menggunakan sensor Tegangan dan sensor getaran sebagai pendeteksi aksi pencurian, dimana logika yang digunakan untuk menetukan aksi pencurian dengan melihat output dari sensor getaran dan tegangan. Jika nilai yang dibaca dari sensor getaran sama dengan high atau nilai yang dibaca oleh sensor tegangan besar sama dengan $9 \mathrm{~V}$, maka mikrokontroler akan mengaktifkan buzzer dan mengintruksikan modul GSM SIM800 untuk mengirim notifikasi berupa SMS kepada pemilik. [2]

Berbeda dengan Husnibes Muchtar dan Bayu Firdaus pada tahun 2017 dimana mengembangkan sistem keamanan tambahan pada kendaraan sepeda motor dengan menggunakan SMS gateway dan modul GPS yang kemudian sistem alarm panggilan telepon terdapat perbedaan respon tergantung dari penggunaan kartu SIM. Semakin mendekati 0 (Nol) nilai $\mathrm{dBm}$ semakin kuat sinyal tersebut. Namun pada hasil pengujian diatas nilai $\mathrm{dBm}$ yang paling jauh dari Nol justru memiliki respon paling cepat. Hal ini dapat dimungkinkan terjadi karena modul GSM lebih cepat mendapatkan koneksi dengan menggunakan kartu SIM tersebut walaupun sinyalnya lebih lemah dibanding dengan yang lain dan faktor kestabilan sinyal sangat berpengaruh terhadap waktu yang dibutuhkan modul GSM untuk terkoneksi dengan jaringan. [3]

Pada di tahun 2018 Arycca Septian Mulyana dan kawan-kawan mengembangkan sistem keamanan pada motor dengan menggunakan sensor sidik jari, modul SIM900A, modul GPS SKM53, modul relay 1 channel, power supply berupa aki dan LCD 16x4. , pada penelitian yang mereka laksanakan memanfaatkan teknologi SMS gateway, pemidaian sidik jari dan aplikasi pada smartphone untuk memudahkan pengguna menggunakan sistem kemanan kendaraan roda dua ini dan menggunakan metode state machine dalam program sistemnya. Dan Tingkat keberhasilan yang dihasilkan dengan menerapkan State Machine dinyatakan berhasil dengan nilai tingkat keberhasilan keseluruhan sistem adalah $88,46 \%$. Dengan semua modul yang digunakan dapat berjalan dengan baik. [4].

Termasuk Rino Reifano Rachmat dan juga E. Shintadewi Julian merancang sebuah sistem keamanan pada sepeda motor pada tahun 2016 yang berbasis mikrokotroler dengan menggunakan modem GSM serial wavecom M1306B perlu dilengkapi dengan kartu GSM yang operatornya akan disesuaikan dengan operator GSM yang digunakan oleh pengguna. Pada saat sensor kunci motor dihidupkan tanpa menonaktifkan rahasia, maka alarm berbunyi, CDI mati dan modem GSM mengirimkan SMS serta melakukan panggilan telepon ke handphone sebanyak 3 kali. [5]

\subsection{Mikrokotroller Arduino Uno}

Arduino Uno adalah board mikrokontroler berbasis ATmega328. Memiliki 14 pin input dari output digital dimana 6 pin input tersebut dapat digunakan sebagai output PWM dan 6 pin input analog, $16 \mathrm{MHz}$ osilator kristal, koneksi USB, jack power, ICSP header, dan tombol reset. Untuk mendukung mikrokontroler agar dapat digunakan, cukup hanya menghubungkan Board Arduino Uno ke komputer dengan menggunakan kabel USB atau listrik dengan AC yang-ke adaptor-DC atau baterai untuk ++`menjalankannya.

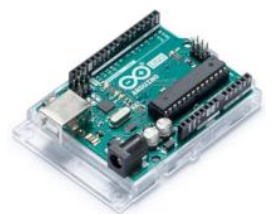

Gambar 1 Arduino Uno ATmega328

\subsection{Modul GPS Neo 6m}

Seri modul NEO-6 adalah keluarga penerima GPS yang berdiri sendiri yang menampilkan mesin ublox 6 kinerja tinggi. Penerima yang fleksibel dan hemat biaya ini menawarkan banyak pilihan konektivitas dalam paket miniatur 16 x 12.2 x 2.4 $\mathrm{mm}$. Arsitekturnya yang ringkas dan opsi daya dan memori menjadikan modul NEO-6 ideal untuk 
perangkat seluler yang dioperasikan dengan baterai dengan batasan biaya dan ruang yang sangat ketat. Mesin pemosisian u-blox 6 saluran 50-kanal menawarkan Time-To-First-Fix0 (TTFF) dari di bawah 1 detik. Mesin akuisisi khusus, dengan 2 juta korelator, mampu melakukan pencarian ruang waktu / frekuensi paralel masif, memungkinkannya menemukan satelit secara instan.

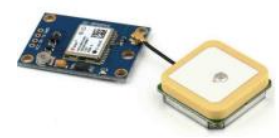

Gambar 2 Modul GPS Neo 6m

\subsection{Modul GSM SIM800L}

Modul GSM SIM800 adalah perangkat yang bisa digunakan untuk menggantikan fungsi handphone. Untuk komunikasi data antara sistem jaringan seluler, maka digunakan Modul GSM SIM800 yang digunakan sebagai media panggilan telephone celluler. Protokol komunikasi yang digunakan adalah komunikasi standart modem yaitu AT Command. Modul SIM800 di Indonesia banyak digunakan pada industri bisnis rumahan dan bahkan skala besar, mulai dari fungsi untuk controller berbasis SMS, WEB, Call sistem hingga sebagai penggerak perangkat elektronik jarak jauh.

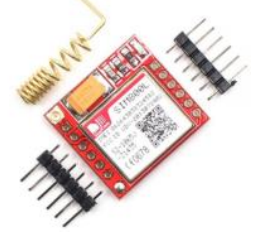

Gambar 3 Modul GSM SIM800L

\subsection{Sensor Sidik Jari AS608}

Fingerprint adalah sebuah alat elektronik yang menerapkan sensor scanning untuk mengetahui sidik jari seseorang guna keperluan verifikasi identitas. Sensor Fingerprint seperti ini digunakan pada beberapa peralatan elektronik seperti smartphone, pintu masuk, alat absensi karyawan dan berbagai macam peralatan elektronik yang membutuhkan tingkat keamanan yang tinggi, dan hanya bisa di akses oleh orang - orang tertentu saja. Sebelum sensor Fingerprint ditemukan, dahulu sebuah data di amankan dengan menggunakan password atau ID, ada juga yang menggunakan pola guna mengamankan suatu data.

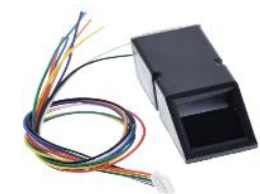

Gambar 3 Sensor Sidik Jari AS608

\subsection{Relay}

Relay adalah suatu alat yang bekerja berdasarkan elektromagnetik untuk menggerakan sejumlah kontaktor yang tersusun atau sebuah saklar elektronis yang dapat dikendalikan dari rangkaian elektronik lainnya dengan memanfaatkan tenaga listrik sebagai sumber energinya. Kontaktor akan tertutup (menyala) atau terbuka (mati) karena efek induksi magnet yang dihasilkan kumparan (induktor) ketika dialiri arus listrik. Berbeda dengan saklar, pergerakan kontaktor (on atau off) dilakukan manual tanpa perlu arus listrik. Relay yang paling sederhana ialah relay elektromekanis yang memberikan pergerakan mekanis saat mendapatkan energi listrik. Secara sederhana relay elektromekanis ini didefinisikan sebagai Saklar yang digerakkan secara mekanis oleh daya atau energi listrik.

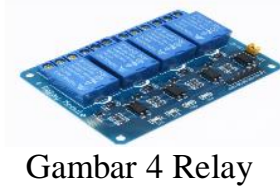

\subsection{Buzzer}

Buzzer merupakan komponen elektronika yang masuk dalam keluarga transduser, yang dapat mengubah sinyal listrik menjadi getaran suara. Nama lain dari komponen ini disebut dengan beeper, dalam kehidupan sehari-hari, umumnya digunakan untuk rangkaian alarm pada jam, bel rumah, perangkat peringatan bahaya, dan lain sebagainya. Jenis - jenis yang sering ditemukan dipasaran yaitu tipe piezoelectric. Dikarenakan tipe ini memiliki kelebihan seperti harganya yang relatif murah, mudah diaplikasikan ke dalam rangkaian elektronika.

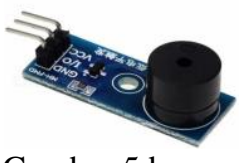

Gambar 5 buzzer

\section{METODE PENELITIAN}

\subsection{Analisis Kebutuhan}

Kebutuhan dalam sistem keamanan pada kelistrikan motor ini mencakup dua hal yaitu kebutuhan fungsional dan kebutuhan non fungsional. Berikut ini adalah penjabaran kebutuhan-kebutuhan tersebut.

\subsubsection{Kebutuhan Fungsional}

Pada sistem keamanan pada kelistrikan motor ini memiliki kebutuhan Fungsional yaitu:

1. Sistem mampu mengirim notifikasi dan menampilkan lokasinya

2. Sistem mampu mengontrol kelistrikan pada sepeda motor

3.3.2 Kebutuhan Non Fungsional Pada sistem keamanan pada kelistrikan motor ini memiliki kebutuhan Fungsional yaitu:

1. Alat ini dibuat seminimalis mungkin sehingga memudahkan dalam proses penggunaan dan pemasangannya.

2. Sistem akan lebih optimal bila diterapkan di luar ruangan 


\subsection{Blok Diagram Sistem}

Blok diagram adalah diagram dari sebuah sistem, di mana bagian modul gsm sebagai alat masukan untuk mendeteksi lokasi, Arduino Uno Sebagai alat pemrosesan, lalu modul gsm untuk mengirim lokasi setelah itu finger print di gunakan untuk membuka relay dan aki sendiri merupakan caru daya untuk untuk Arduino itu sendiri. Proses kerja pada alat ini di tunjukkan pada Gambar 2

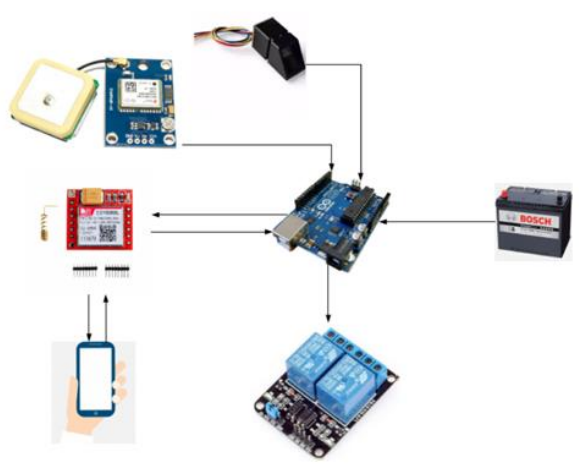

Gambar 6 Blok diagram sistem

\subsection{Flowchart Sistem}

Flowchart sistem ini menjelaskan proses berjalananya alat seperti ditunjukkan pada Gambar 7.

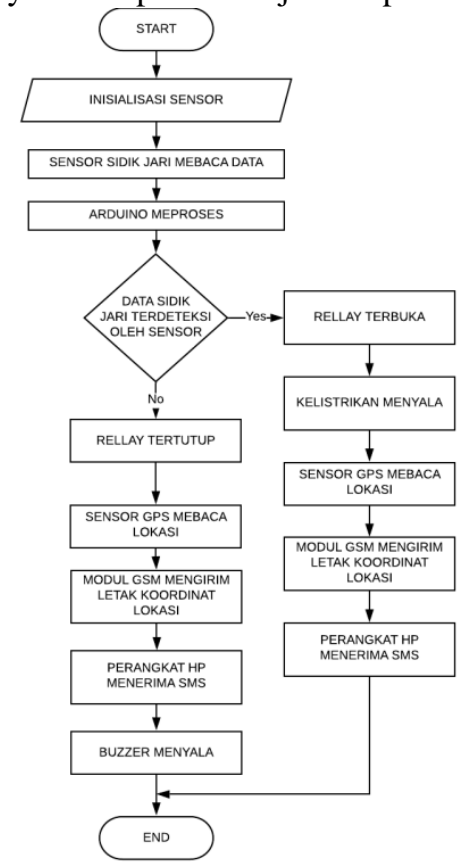

\section{Gambar 7 Flowchart Sistem}

Pada flowchart di atas sistem dimulai dengan inisiai sensor dan variable, sensor sidik jari akan mendeteksi sidik jari yang sudah terekam lalu akan diproses di arduino setelah itu jika sidik jari terdeteksi bahwa benar maka arduino akan memberi perintah untuk membuka gerbang relay agar kelistrikan motor menyala lalu modul GPS akan membaca lokasi saat itu dan mengirim informasi melalui modul gsm dalam bentuk SMS. Jika tidak terdeteksi makan arduino akan memberi perintah kepada relay untuk tetap menutup gerbang dan modul GPS akan membaca lokasi saat itu dan mengirim informasi bahwa sidik jari tidak terdeteksi ditambah secara otomatis buzzer akan bunyi selama beberapa menit.

\section{HASIL DAN PEMBAHASAN}

\subsection{Pengujian Model Design}

Pengujian ini merupakan pengujian hardware pada alat yang sudah di kerjakan, lalu dilakukan pada setiap komponen yang terhubung pada setiap minimum sistem arduino.

\subsection{Pengujian Hardware Sensor Sidik Jari}

Pengujian menggunakan sensor sidik jari dengan tipe AS608 ini berfungsi untuk mengetahui kemampuan sensor dan dalam memindai sidik jari, sebelum membandingkan gambar yang baru saja diambil dengan data yang telah disimpan di chip DSP (Digital Signal Processor) yang terletak dalam modul, processor scanner memastikan bahwa CCD (charge-coupled device) telah mengambil gambar yang jelas dengan cara melakukan pengecekan kegelapan rata-rata piksel, secara umum sensor sidik jari mempunyai prinsip kerja yaitu, pendaftaran sidik jari atau enroll, lalu ada database sebagai penyimpanan data pendaftaran ID dan pencocokan (matching).

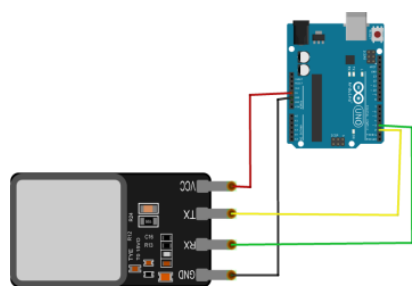

Gambar 8 Rangkaian Pengujian Sensor Sidik Jari

Gambar 8. Merupakan rangkaian dari sensor sidik jari AS608 yang dihubungkan ke minimum sistem arduino menggunakan kabel jumper. Pin VCC dari sensor sidik jari dihubungkan ke pin VCC $5 \mathrm{~V}$ arduino. Pin GND dari modul sensor sidik jari dihubungkan ke pin GND dari arduino. Pin TX dari sensor sidik jari dihubungkan ke pin 2 dan pin RX dihubungkan ke pin 3 Arduino

Tabel 1 Hasil Pengujian Sensor Sidik Jari

\begin{tabular}{|c|c|c|c|c|c|c|}
\hline No & TANGAN & JARI & TERDAFTAR & D & $\begin{array}{c}\text { HASL } \\
\text { PENCOCOKAN } \\
\text { SDIK JARI }\end{array}$ & $\begin{array}{c}\text { WAKTU } \\
\text { PEMBACAAN } \\
\text { DETEKSI } \\
\text { SDIK JARI } \\
\end{array}$ \\
\hline 1 & \multirow{5}{*}{ KANAN } & JEMPOL & $\checkmark$ & 1 & TERDETEKSI & 1.88 Detik \\
\hline 2 & & TELUNJUK & $\checkmark$ & 2 & TERDETEKSI & 1.91 Detik \\
\hline 3 & & TENGAH & $\checkmark$ & 3 & TERDETEKSI & 1.85 Detik \\
\hline 4 & & MANIS & $\checkmark$ & 4 & TERDETEKSI & 1.88 Detik \\
\hline 5 & & KELINGKING & - & - & $\begin{array}{c}\text { TIDAK } \\
\text { TERDETEKSI }\end{array}$ & 1.74 Detik \\
\hline 1 & \multirow{5}{*}{ KIRI } & JEMPOL & $\checkmark$ & 5 & TERDETEKSI & 1.90 Detik \\
\hline 2 & & TELUNJUK & $\checkmark$ & 6 & TERDETEKSI & 1.85 Detik \\
\hline 3 & & TENGAH & - & - & $\begin{array}{c}\text { TIDAK } \\
\text { TERDETEKSI }\end{array}$ & 1.73 Detik \\
\hline 4 & & MANIS & - & - & $\begin{array}{c}\text { TIDAK } \\
\text { TERDETEKSI }\end{array}$ & 1.75 Detik \\
\hline 5 & & KELINGKING & - & - & $\begin{array}{c}\text { TIDAK } \\
\text { TERDETEKSI }\end{array}$ & 1.80 Detik \\
\hline
\end{tabular}


Pada tabel 1 yang dimana berisi hasil pengujian terhadap sensor sidik jari AS608, sebelum melakukan pengujian sidik jari harus sudah terdaftar di sensor sidik jari itu sendiri dan dalam pengujian sensor sidik jari ini penulis mendaftar sidik jarinya sendiri dan sebagian jari dengan sengaja tidak di daftarkan agar dapat mengetahui hasil dari pengujian sensor sidik jari ini. Dalam pengujian ini sendiri menggunakan serial monitor yang terdapat di Arduino dan menggunakan stopwatch yang terdapat di handphone android untuk mengukur waktu respon pembacaan deteksi sidik jari. Dalam kerja sensor sidik jari sendiri juga memerlukan waktu berkisar 1.85 detik untuk proses dalam memindai sidik jari dari pengambilan gambar hingga pencocokan data yang telah tersimpan di memori sensor untuk menentukan apakah sidik jari yang di pindai ini terdeteksi atau tidak terdeteksi dan di tampilkan di serial monitor seperti di gambar.

\subsection{Pengujian Modul GPS Neo 6m}

Pengujian menggunakan modul GPS Neo-6m berfungsi untuk mengetahui tingkat keakuratan dalam pembacaan lokasi. Nilai yang dihasilkan dari pembacaan modul GPS ini adalah berupa koordinat Lattitude dan Longitude. Hasil dari pengujian modul GPS ini akan dibandingkan dengan hasil pembacaan lokasi menggunakan Smartphone Asus Zenfone 3. Berikut skema rangkaian alat beserta hasil pengujian Modul GPS Neo-6m.

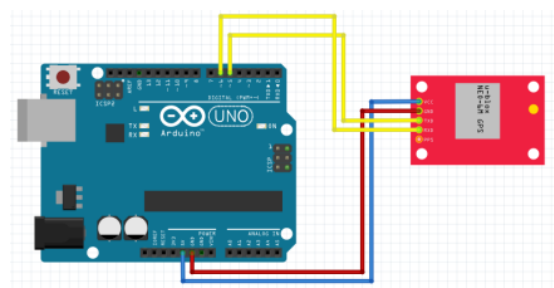

Gambar 9 Rangkaian Pengujian Modul GPS

Gambar 10 diatas merupakan gambar rangkaian dari modul GPS Neo-6m yang dihubungkan ke minimum sistem arduino menggunakan kabel jumper. Pin VCC dari modul GPS dihubungkan ke pin VCC 5 $\mathrm{V}$ arduino. Pin GND dari modul GPS dihubungkan ke pin GND dari arduino. Pin TX dari modul GPS dihubungkan ke pin 5 dan pin RX dihubungkan ke pin 6 Arduino. Ada pula hasil pengujian dari modul ini.

Tabel 2 Hasil Pengujian Modul GPS NEO 6m

\begin{tabular}{|c|c|c|c|c|c|c|c|}
\hline \multirow{2}{*}{ No } & \multicolumn{2}{|c|}{ Pengujian Modul } & \multicolumn{2}{|c|}{ Pengujian Andorid } & \multirow{2}{*}{$\begin{array}{l}\text { Jarak } \\
\text { A (m) }\end{array}$} & \multirow{2}{*}{$\begin{array}{l}\text { Jarak } \\
\text { B (m) }\end{array}$} & \multirow{2}{*}{$\begin{array}{c}\text { Selisih } \\
\text { (m) }\end{array}$} \\
\hline & Latittude & Longtitude & Latittude & Longtitude & & & \\
\hline 1 & -7.921646 & 112.621299 & -7.921625 & 112.621284 & 2 & 0.002868 & 1.9 \\
\hline 2 & -7.921646 & 112.621299 & -7.921625 & 112.621284 & 2 & 0.002868 & 1.9 \\
\hline 3 & -7.921638 & 112.621292 & -7.921625 & 112.621284 & 1 & 0.001699 & 0.9 \\
\hline 4 & -7.921638 & 112.621292 & -7.921625 & 112.621284 & 1 & 0.001699 & 0.9 \\
\hline 5 & -7.921655 & 112.621292 & -7.921625 & 112.621284 & 2 & 0.003456 & 1.9 \\
\hline \multicolumn{7}{|c|}{ Rata - Rata } & 1.5 \\
\hline
\end{tabular}

Pada tabel 2 Menghitung selisih jarak 2 titik koordinat pada peta menggunakan Euclidian. (1 derajat bumi $=111.319 \mathrm{~km}$ )

$$
\begin{aligned}
& d=\sqrt{(x 1-x 2)^{2}+(y 1-y 2)^{2}} * 111.319 \\
& \text { Keterangan : } \\
& \text { X1 : Lattitude dari modul } \\
& \text { X2 : Lattitude dari Google maps } \\
& \text { Y1 : Longitude dari modul } \\
& \text { Y2 : Longitude dari Google maps } \\
& \text { Jarak A :Tracking menggunakan Google map } \\
& \text { Jarak B : Perhitungan Ecluidian } \\
& 111,319 \mathrm{~km} \text { : nilai } 1^{\circ} \text { (derajat) bumi } \\
& \text { Contoh Perhitungan : } \\
& d=\sqrt{(-7.921646-(-7.921625))^{2}}+(112.621299-112.621284)^{2} \times 111.319 \\
& d=\sqrt{(}-0.000021)^{2}+0.000015^{2} \times 111.319 \\
& d=\sqrt[111.319]{\left(-\frac{21}{1000000}\right)^{2}+\left(\frac{3}{200000}\right)^{2}} \\
& d=\sqrt[111.319]{\frac{441}{1000000^{2}}+\left(\frac{3}{200000}\right)^{2}} \\
& d=0.002868
\end{aligned}
$$

Pada tabel pengujian di atas dilakukan dengan cara mendapatkan koordinat lokasi masing-masing dari modul GPS dan google maps. Pengujian yang pertama di tracking menggunakan google map. Selanjutnya dilakukan pengujian dengan menggunakan perhitungan Euclidian dengan menghitung jarak modul GPS dan google maps. Dengan hasil rata-rata dari perbandingan jarak $\mathrm{A}$ dengan jarak B yaitu $1.5 \mathrm{~m}$

\subsection{Pengujian Modul GSM SIM 800L}

Pengujian menggunakan modul GSM SIIM 800L ini berfungsi sebagai pengganti dari handphone yang berperan sebagai mengirim sms sebagai pengganti handphone. Sistem ini juga telah dilengkapi oleh simcard seperti layaknya handphone yang biasa kita pakai. Untuk menjalankan alat ini diperlukan tegangan 3.7 volt dan arus sebesar $2 \mathrm{~A}$, tegangan ini sesuai dengan datasheet yang didapat oleh penulis, lalu ada $L E D$ di sisi kanan atas modul GSM SIM800L yang menunjukkan status jaringan seluler. $L E D$ ini akan berkedip pada berbagai tingkat untuk menunjukkan keadaannya, jika berkedip tiap 1 detik sekali maka modul ini berjalan namun belum membuat koneksi pada jaringan seluler, jika berkedip setiap 2 detik sekali maka data GPRS sudah aktif dan jika LED berkedip 3 detik sekali maka telah melakukan kontak dengan jaringan seluler \& dapat mengirim / menerima suara dan pesan. Dan pengujian ini di lakukan dengan menggunakan AT COMMAND, Berikut skema rangkaian alat beserta hasil pengujian Modul GSM SIM 800L 


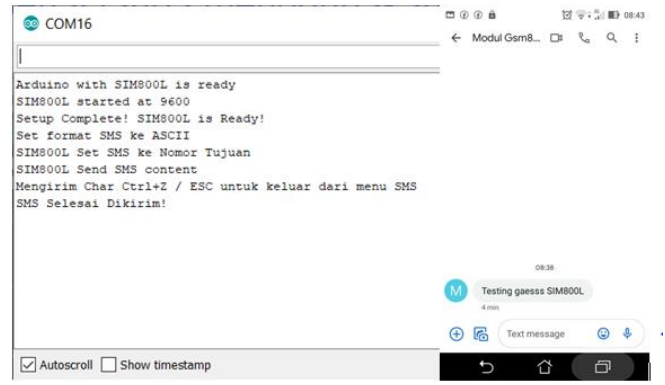

Gambar 10 Hasil Pengujian Modul GSM SIM 800L

\subsection{Pengujian Hardware}

Pengujian komponen dari alat proteksi motor ini terdiri dari minimum sistem Arduino Uno, Modul GPS Neo 6M, Modul GPS Neo 6m, dan Relay. Implementasi komponen yang terhubung pada minimum sistem arduino diletakkan pada sebuah box yang nantinya ditempatkan di dalam sepeda motor. Adapaun implementasi hardware pada gambar 12

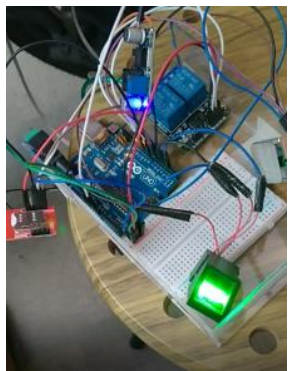

Gambar 11 Hasil Pengujian Hardware

Tabel 3 Hasil Pengujian Hardware

\begin{tabular}{|c|c|c|c|c|c|}
\hline NO & $\begin{array}{c}\text { Perintah } \\
\text { SMS }\end{array}$ & Balasan SMS & DELAY & $\begin{array}{c}\text { Kondisi } \\
\text { Relay }\end{array}$ & Lokasi \\
\hline 1 & $\begin{array}{c}\text { MOTOR } \\
\text { ON }\end{array}$ & Motor Bisa Dinyalakan & 3 Detik & $\begin{array}{c}\text { Relay_ } \\
\text { ON }\end{array}$ & - \\
\hline 2 & $\begin{array}{c}\text { MOTOR } \\
\text { OFF }\end{array}$ & Motor Dimatikan & 4 Detik & $\begin{array}{c}\text { Relay_ } \\
\text { OFF }\end{array}$ & - \\
\hline 3 & $\begin{array}{c}\text { Cek } \\
\text { Lokasi }\end{array}$ & - & - & - & - \\
\hline 4 & $\begin{array}{c}\text { Cek } \\
\text { Lokasi }\end{array}$ & $\begin{array}{c}\text { https://www.google.com } \\
/ \text { maps?q=- } \\
7.921646,112.621299\end{array}$ & 4 Detik & - & $\begin{array}{c}-7.921646 \\
112.62129 \\
9\end{array}$ \\
\hline
\end{tabular}

Pada tabel 3 merupakan tabel hasi pengujian dimana kerja alat ini menggunakan media handphone untuk memberikan perintah yang berbentuk sms, lalu alur kerja alat ketika sudah terinisialisasi, lalu sensor gps dan modul gsm telah mendapatkan sinyal maka user akan menerima sms berupa " alat ready " yang dimana menandakan bahwa alat siap di gunakan saat di beri perintah " motor on " maka relay akan terbuka dan sepeda motor akan siap untuk dinyalakan, lalu jika di beri perinta " motor off " maka relay akan tertutup dan sepeda motor akan mati dan tidak dapat di starter. Lalu jika di beri perintah "Cek Lokasi" maka alat akan mengirim letak koordinat dalam bentuk link yang bisa di akses melalui google maps. Dalam memberi perintah "Cek Lokasi" harus di pastikan bahwa modul gps sudah menerima sinyal di karenakan jika modul gps belum menerima sinyal dari satelit maka modul gps tidak dapat memberin titik lokasi dan modul gsm tidak akan merespon perintah "Cek Lokasi" karena modul gps tidak mendapatkan sinyal dari satelit seperti yang terjadi di tabel no tiga

\section{KESIMPULAN DAN SARAN \\ 5.1 Kesimpulan} bahwa :

Dari percobaan penelitian ini dapat disimpulkan

1. Berdasarkan hasil perancangan sitem, implementasi hingga pengujian yang memanfaatkan sms gateway dari modul GSM dan melacak lokasi dengan modul GPS dengan rentan waktu 3 hingga 4 detik.

2. Hasil pengujian sensor sidik jari dengan menggunakan serial monitor dan stopwatch, respon dari sensor untuk memindai sidik jaro yaitu dengan waktu 1.83 detik

3. Hasil pengujian modul GPS dengan smartphone menggunakan tracking google map dan perhitungan Euclidian menghasilkan rata-rata selisih jarak $1,5 \mathrm{~m}$

4. Pada modul GSM SIM 800L di perlukan komponen tambahan yaitu DC converter, agar modul GSM SIM $800 \mathrm{~L}$ dapat mengirim atau menerima sms membutuhkan tegangan $3.7 \mathrm{~V}$ dan arus sebesar $2 \mathrm{~A}$

\subsection{Saran}

Sistem keamanan yang di implementasikan di sepeda motor ini masih memiliki kekurangan, sehingga bisa dikembangkan agar menjadi lebih sempurna. Adapun beberapa saran yang dapat dikembangkan

1. Penambahan geocoding lokasi untuk untuk memperjelas alamat yang dihasilkan oleh sensor GPS

2. Memperkecil ukuran pembuatan sistem keamanan dan membuat satu tempat khusus agar mudah di pasang di sepeda motor

3. Menambahkan platfrom android dalam bentuk aplikasi sehingga mampu di monitoring oleh pengguna lain

\section{DAFTAR PUSTAKA}

[1] Fernando Napitupulu., Ekki Kurniawan, S.T., M.S.c, \& Cahyani Ekaputri, S.T. M.T. (2017) Desain dan implementasi sistem keamanan pada sepeda motor berbasi mikrokontroller, Teknik elektro, Telkom University Pratama, Muhammad Rizki, 2016, Implementasi Fuzzy Logic dalam Perancangan Drum Elektrik Berbasis Midi Menggunakan Perangkat Android dan Arduino Uno, Jurnal Ilmu Komputer

[2] Andesta, D., \& Ferdian, R. (2018, September 29). Sistem Keamanan Sepeda Motor Berbasis Mikrokontroler dan Modul GSM. JITCE (Journal of Information Technology and Computer Engineering) Faisal. 2017, Rancang Bangun Perangkat Drum Elektrik Berbasis 
Mikrokontroler Dengan Memanfaatkan Bahan Pelastik, Jurnal Teknik Informatika, Maret 2017

[3] PrHusnibes Muchtar, \& Bayu Firdaus (2017), PERANCANGAN SISTEM KEAMANAN TAMBAHAN PADA KENDARAAN SEPEDA MOTOR BERBASIS APLIKASI ANDROID DENGAN MENGGUNAKAN MIKROKONTROLLER, Teknok Elektro, Universitas Muhammadiyah Jakarta
[4] Arycca Septian Mulyana, Wijaya Kurniawan, \& Gembong Edhi Setyawan (2018). Perancangan Sistem Keamanan Motor Dengan Menggunakan State Machine. Teknik Informatika, Fakultas Ilmu Komputer, Universitas Brawijaya.

[5] Rino Reifano Rachmat \& E. Shintadewi Julian (2016). Pengaman sepeda motor berbasis mikrokontroller. Teknik Elektro, Universitas Trisakti 